\title{
Induced Abortion and Its Predictors Among Hawassa University Female Students
}

\author{
Yohannes Fikadu Geda ${ }^{1}$, Walelign Animut Tirfe ${ }^{2}$, Molalign Mesele Gessese ${ }^{2}$ \\ ${ }^{1}$ Department of Midwifery, College of Medicine and Health Science, Wolkite University, Wolkite, Ethiopia \\ ${ }^{2}$ Department of Midwifery, College of Medicine and Health Science, Wolaita Sodo University, Sodo, Ethiopia \\ Email address: \\ nechsar@gmail.com (Y.F. Geda), endua2020@gmail.com (W. A. Tirfe), molalegn.mesele@gmail.com (M. M. Gessese)

\section{To cite this article:} \\ Yohannes Fikadu Geda, Walelign Animut Tirfe, Molalign Mesele Gessese. Induced Abortion and Its Predictors Among Hawassa University \\ Female Students. International Journal of Immunology. Vol. 8, No. 3, 2020, pp. 53-60. doi: 10.11648/j.iji.20200803.13
}

Received: March 2, 2020; Accepted: March 19, 2020; Published: October 27, 2020

\begin{abstract}
Global incidence of unsafe abortion among University students is increasing; and still frequent and worrisome in Universities of Ethiopia. There are a few studies on induced abortion among university students. There for this study was aimed to determine magnitude and predictors of induced abortion among Hawassa University female students. Institution based cross-sectional study was conducted from May 1-15, 2019 and 741 participants were selected from Hawassa University regular undergraduate female students. For entry and analysis EPidata and SPSS was used respectively. Association between dependent and independent variables were measured by adjusted odds ratio. Variables with $p<0.25$ on bivariate were used for multivariable analysis and $\mathrm{p}<0.05$ were considered significant. Magnitude of induced abortion among Hawassa University students was $9.6 \%$. From the respondents $68 \%$ of them age greater or equal to 20 (AOR=0.32, 95\% CI: $0.14,0.74)$ were less likely to have induced abortion compared to those respondents with age less than or equal to 19. Married respondents were 3.32 times $(\mathrm{AOR}=3.32,95 \% \mathrm{CI}: 1.51,7.28)$ more likely to have induced abortion compared to not married respondents. From the respondents $95 \%$ of them who have heard only about short term contraceptive $(\mathrm{AOR}=1.95,95 \% \mathrm{CI}: 1.04,3.66)$ were more likely to have induced abortion compared to those who have heard only about long term contraceptives. Respondents who have used methods to avoid pregnancy currently were 5.41 times $(\mathrm{AOR}=5.41$, 95\% CI: $2.73,10.72$ ) more likely to have induced abortion compared to who haven't used any method. Induced abortion among Hawassa university female student was high compared to other studies. This study showed the independent predictors of abortion among Hawassa University students were age, marital status, type of contraceptive they know and using any method to avoid pregnancy currently.
\end{abstract}

Keywords: Induced Abortion, Student, Sexual Health of Youth, University, Hawassa

\section{Introduction}

\subsection{Background}

Induced abortion is an intentional termination of pregnancy by any means or person other than spontaneous miscarriage [1]. Women usually under-report their abortion experiences, mainly because abortion is a sensitive and controversial issue with religious, moral, cultural, political and scopes other reasons in many countries across the world [2-5]. World Health Organization (WHO) estimates that one woman dies every eight minutes due to unsafe abortions; consequently around five million women who undergo unsafe abortions require hospitalization [6-8].
The world attains 42 million induced abortions annually almost all of this is induced abortion [2, 10]. Worldwide, around 120 million women annually need contraception but it is not accessible to them; parallel with this, approximately 250 million pregnancies occur and one-third of them are unintended; out of them $20 \%$ are terminated as induced abortion [6]. More than one-fourth of the world's people live in rural areas where the procedure is not allowed or allowed only to preserve the woman's life $[6,11]$.

Most of women undergoing induced abortion have no previous births preceding abortion $[12,13]$. Unsafe abortion is a significant but preventable cause of global maternal mortality and morbidity [14]. Utilization of family planning is very crucial to decrease unintended pregnancy and unsafe 
abortion which in turn reduces maternal morbidity and mortality $[7,8,15]$. However, there is limited understanding over the counseling needs of women accessing abortion services, particularly in sub-Saharan Africa [16].

Ethiopia government revised the laws of abortion in 2005 that had permitted induced abortion with certain conditions like: if woman's pregnancy could create health problems on her, if the fetus had conditions incompatible with life, or if the conceived pregnancies were from incest, rape or minor groups [3, 17]. However, irrespective of legal status, abortions still occur and increasing from time to time and nearly half of them are performed by an unskilled practitioner or in less than sanitary conditions, or both [12, $18]$.

Even if restrictive laws often render safe abortions more difficult to acquire, they are frequently ineffective at minimizing the incidence of abortion $[19,20]$. In case the restrictive law reduces induced abortion rate it could have the unintended consequence $[21,22]$. But it is publicly known that number of countries in the world legalize abortion without restriction [23], however this alone does not guarantee access to safe abortion, and $30 \%$ of maternal mortality is attributable to unsafe procedures [14].

\subsection{Statement of the Problem}

Updated reports show that around $13 \%$ of maternal deaths are the result of unsafe abortion in the globe $[1,24]$. Overall, $10 \%-15 \%$ of abortions worldwide occur in the second trimester, this account for a disproportionate number of maternal deaths when provided under unsafe conditions [25]. Health sequel of unsafe abortion account for an estimated $7.9 \%$ of global maternal mortality and maternal deaths among Sub-Saharan Africa is $9.6 \%(19,26)$.

In Africa, about one in every seven pregnancies (15\%) ends in an induced abortion [27]. Unsafe abortion is a leading cause of death among young women's in sub-Saharan Africa [28. Both the incidence and health burden of unsafe abortions are disproportionately concentrated in low income countries, where approximately $97 \%$ of the 25 million annual unsafe abortions occur [19].

The ages at which women have induced abortion is a significant factor [29]. A study shows that the interviewed women decided to terminate their pregnancies for different reasons like poverty, poor timing of the pregnancy and absence of support from male partners [15]. Women's reasons for induced abortions represented their vulnerability types at the critical time of decision making [30]. In addition to this absence of planning programs and more information and access to contraception methods were the risk factors of induced abortion [31]. Women's knowledge of abortion legislation is a significant determinant of the utilization of safe abortion services [32].

The 2030 Agenda for Sustainable Development renewed the commitments by 193 Member States of the United Nations (UN) to reduce global maternal mortality through universal access to sexual and reproductive health (SRH) services, education and information [33, 34]. Over six million induced abortions were reported in Africa with over two million induced abortions occurring in Eastern Africa [28].

Although the Ethiopia has expanded access to abortion and post abortion care, the last estimates of abortion incidence date from 2008 [28]. According to a study more than $32 \%$ of maternal mortality reported in Ethiopia is due to unsafe abortions [32]. The overall magnitude of unintended pregnancy in Ethiopia is about 42\%; 3.27 million estimated pregnancies, half a million ends up in abortion [1].

Even some studies done in Ethiopia, which shows the magnitude and associated factors for induced abortion at community and facility base, but there is limitation of studies done on the magnitude and associated factors for induced abortion among University students. So that this study were planned to show the magnitude and predictors of induced abortion among Hawassa University female students. This will help for the policy makers and program implementers to consider the prevention of repeat induced abortion and its associated factors at facility and community based level.

\section{Main Body}

\subsection{Methods and Materials}

The study was conducted in Hawassa University (HU) located in Hawassa City. Hawassa is the capital city of southern nations nationality peoples region (SNNPR) located at $275 \mathrm{~km}$ south to Addis Ababa, the capital city of Ethiopia. Hawassa's climatic condition is woinadega and has 280,000 populations. Currently, Hawassa University has seven functional campuses, within it seven campuses, HU operates 8 Colleges and 1 Institute. HU runs 81 Undergraduate degree programmes, 108 Masters and $16 \mathrm{PhD}$ programmes in its 41 Schools and Departments. The student population as of March 2018 is 48,558 (of which $28.86 \%$ are female) [37].

Institutional based crossectional study was conducted from May 1-15, 2019. Hawassa university undergraduate female students were the source population of this study and selected female students of Hawassa University during data collection period were the study population.

The required sample size for the first objective was calculated using single population proportion formula and with an assumption of $95 \%$ confidence interval, 5\% margin of error, a proportion of $32.4 \%$ from study done at Medawalabu University, Ethiopia on induced abortion [38] making 673. Adding $15 \%$ contingency to account for nonresponse rate yielded a final sample size of 774 .

For the second objective various Sample sizes were calculated based on proportions of different variables from literatures using Open Epi statistical software Version 3.03 considering the assumptions: $80 \%$ power of the study, $95 \%$ confidence and ratio of unexposed to exposed 1:1. Of thus calculated sample sizes the one with the highest sample size was taken by considering 2 for design effect and $15 \%$ contigency, but the samples were less than sample size of the first objectictiv. Since sample size for the first objective is 
greater it was used in this study.

Stratified multistage sampling technique was used, and the procedure was as follows. There are eight colleges in Hawassa university; this colleges were divided in to two practical strata as health and non-health colleges. Simple random sampling method was applied to select three representatives of non-health colleges, and sample size was allocated to the stratified colleges proportional to their size (PPS). Next three representative departments from each non health and health colleges have been included and then class years are stratified as first, second, third, fourth and above. The total sample size were again allocated to each class year probability proportional to size (PPS), finally 774 students were selected by Simple Random Sampling (SRS) technique using identified females ID accessed from each collage registrar.

The data were collected by self-administered pretested questionnaires. Twelve data collectors and two supervisors were recruited. Moreover, practical exercises have been done by data collectors during training with the principal investigator how to introduce mentioned issues. Data collection was done by arriving at the end of the scheduled time based on the block number, lecture room number and time to collect data was arranged by communicating with department head and instructor who own each class during data collection time.

For the students purpose of the study, confidentiality and the need for providing honest answers was clarified. After necessary introduction was made the students have had informed how they were selected. Female students who were not included in the study and all male students were ordered to leave the class. In addition to specific instructions on the questionnaire, participants were given clear oral guidance on filling out the questionnaire.

Sitting arrangement was rearranged to make the process confidential and then questioners were distributed in the same time for all students in the same college and they have given similar time to finalize. They also ensured complete privacy during completing the questionnaire. Supervision of the data collection process was done by supervisors along with the principal investigator.

The questionnaire was prepared in English (instructional media of the university) as well as in Amharic languages. Training was given to data facilitators who are masters students and the supervisors before the actual data collectionon on how to approach and select the study participants, on the objective of the study and the content of the questionnaire. To check the clarity, consistency, skipping pattern and order of questions, questionnaire was pre-tested. After pretest, questions were revised, edited, and those found to be unclear were modified.

Data was checked manually for completeness. Then the data were cleaned and stored for consistency after entered in to Epi Data version 3.1 software. For further analysis the data were exported to statistical package for social sciences version 24.0 software. Descriptive statistics were carried out. Bivariate and multivariate analysis was used to see the effect of independent variable over unintended pregnancy. Variables which were significant on bivariate analysis at pvalue less than 0.25 were taken to multivariate analysis. The fitness of model was checked by Hosmer and Lemeshow test. In multivariate analysis $\mathrm{P}$ - value of less than 0.05 and $95 \%$ confidence level was used as a cut of point for presence of association. Finally, results were compiled and presented using tables, graphs, charts and texts.

Ethical clearance were obtained from Hawassa University College of medicine and health science institutional review board (IRB). Permission obtained from academic vice president and registrar and alumni directorate; oral informed consent was obtained from participants. Confidentiality and anonymity were ensured, and participants were informed that their participation would be voluntary.

\subsection{Result}

\subsubsection{Socio-demographic Characteristics of Respondents}

Age of the study participants ranged from 18 to 27 years with a mean age of $20.94 \pm 1.79$, and the age groups $20-24$ constituted $81.2 \%$. Respondents from year one accounts 234 (31.6\%), year two $241(32.5 \%)$, year three $237(32 \%)$ and year four $29(3.9 \%)$ were participated in this study. From this $105(14.2 \%)$ were married and $351(47.4 \%)$ have partner from both in university and out of university (table 1).

Table 1. Socio-demographic characteristics among Hawassa University female students, Hawassa, June 2019-(N=741).

\begin{tabular}{lll}
\hline & Number & Percent \\
\hline Age & & \\
$15-19$ & 109 & 14.7 \\
$20-24$ & 602 & 81.2 \\
$25-29$ & 30 & 4.0 \\
Collages & & \\
Natural and computational science & 290 & 39.1 \\
Agriculture & 171 & 23.1 \\
Social science \& humanity & 147 & 19.8 \\
Medicine and health science & 133 & 17.9 \\
Year of study & & \\
Year one & 234 & 31.6 \\
Year two & 241 & 32.5 \\
Year three & 237 & 32 \\
Year four & 29 & 3.9 \\
Marital status & & \\
Not married & 636 & 85.8 \\
Married & 105 & 14.2 \\
Have partner (N=636) & & \\
Yes & 351 & 47.4 \\
No & 285 & 38.5 \\
Unable to read and write & 40 & 5.4 \\
Place of permanent residence & & \\
Urban & 533 & 71.9 \\
Rural & 208 & 28.1 \\
\hline
\end{tabular}

Most of the respondents 483 (65.2) have had discuss about sexual reproductive health issues; their choice to discuss for majority of the respondents 354 (47.8) were peers. Condom was the most 524 (70.7) known contraceptive method by the 
respondents (table 2).

Table 2. Sexual and reproductive health characteristics among Hawassa University female students, Hawassa, June 2019-(N=741).

\begin{tabular}{lll}
\hline & Number & Percent \\
\hline Issues discussed & & \\
Yes & 487 & 65.7 \\
No & 254 & 34.3 \\
Discussion SRH issues with & & \\
Peers & 354 & 47.8 \\
Partner/husband & 110 & 14.8 \\
Parents & 16 & 2.2 \\
Other* & 7 & 0.9 \\
Types known & & \\
Injectable & 610 & 82.3 \\
Pills & 548 & 74 \\
Condoms & 524 & 70.7 \\
Implants & 504 & 68 \\
IUCD & 446 & 60.2 \\
Calendar & 398 & 53.7 \\
Emergency contraceptive & 398 & 53.7 \\
Other** & 9 & 1.2 \\
Money used will be decided by & & \\
You and Your husband/partner jointly & 160 & 21.6 \\
You & 260 & 35.1 \\
Parents & 240 & 32.4 \\
Your husband/partner & 81 & 10.9 \\
Experience intercourse & & \\
Yes & 249 & 33.6 \\
No & 492 & 66.4 \\
Unintended pregnancy (N=98) & & \\
Yes & 98 & 13.2 \\
No & 643 & 86.8 \\
\hline & & \\
\hline & & \\
\hline
\end{tabular}

\begin{tabular}{lll}
\hline & Number & Percent \\
\hline After entrance to university (N=98) & & \\
Yes & 68 & 9.2 \\
No & 30 & 4 \\
Contraceptives not available & 5 & 0.7 \\
$\begin{array}{l}\text { Outcome of up (N=98) } \\
\text { Terminated }\end{array}$ & 71 & \\
Nothing the UP continues & 27 & 9.6 \\
\hline
\end{tabular}

\subsubsection{Predictors of Induced Abortion}

On bivariate analysis year of study, age, place of permanent residence, marital status, decision to use money, discussion about reproductive health issues, type of contraceptive they heard and using any method to avoid pregnancy were significantly associated with induced abortion. However in multivariate analysis age, marital status, type of contraceptive they heard and using any method to avoid pregnancy stay statistically significant factors associated with induced abortion.

From the respondents $68 \%$ of them age greater or equal to $20(\mathrm{AOR}=0.32,95 \% \mathrm{CI}: 0.14,0.74)$ were less likely to have induced abortion compared to those respondents with age less than or equal to 19. Married respondents were 3.32 times $(\mathrm{AOR}=3.32,95 \% \mathrm{CI}: 1.51,7.28)$ more likely to have induced abortion compared to not married respondents. From the respondents $95 \%$ of them who have heard only about short term contraceptive $(\mathrm{AOR}=1.95,95 \% \mathrm{CI}: 1.04,3.66)$ were more likely to have induced abortion compared to those who have heard only about long term contraceptives. Respondents who have used methods to avoid pregnancy currently were 5.41 times $(\mathrm{AOR}=5.41,95 \% \mathrm{CI}: 2.73,10.72)$ more likely to have induced abortion compared to who haven't used any method (table 3).

Table 3. Predictors of induced abortion among Hawassa University female students, Hawassa, June 2019-(N=741).

\begin{tabular}{|c|c|c|c|c|c|}
\hline \multirow{2}{*}{ Variables } & \multirow{2}{*}{ Category } & \multicolumn{2}{|c|}{ Have induced abortion } & \multirow{2}{*}{$\operatorname{COR}(\mathrm{CI})$} & \multirow{2}{*}{$\operatorname{AOR}(\mathrm{CI})$} \\
\hline & & Yes, N (\%) & No, N (\%) & & \\
\hline \multirow{2}{*}{ Year of study } & Year one & $18(25.4)$ & $216(32.2)$ & $0.71(0.408,1.25)$ & $0.48(0.23,1.01)$ \\
\hline & Year two and above & $53(74.6)$ & $454(67.8)$ & 1 & 1 \\
\hline \multirow{2}{*}{ Age } & $<19$ & $15(21.1)$ & $100(14.9)$ & 1 & 1 \\
\hline & $>20$ & $56(78.9)$ & $570(85.1)$ & $0.65(0.36,1.20)$ & $0.32(0.14,0.74)^{*}$ \\
\hline \multirow{2}{*}{ Place of permanent residence } & Rural & $22(31.0)$ & $186(7.8)$ & $1.17(0.68,1.99)$ & $1.38(0.76,2.49)$ \\
\hline & Urban & $49(69.0)$ & $484(72.2)$ & 1 & 1 \\
\hline \multirow{2}{*}{ Marital Status } & Not married & $60(84.5)$ & $576(86.0)$ & 1 & 1 \\
\hline & Married & $11(15.5)$ & $94(14.0)$ & $1.12(0.45,1.75)$ & $3.32(1.51,7.28)^{*}$ \\
\hline \multirow{4}{*}{$\begin{array}{l}\text { How to use your money } \\
\text { would be decided by } \\
\text { Have you discuss about SRH } \\
\text { issues }\end{array}$} & You & $50(70.4)$ & $498(74.3)$ & $0.82(0.48,1.41)$ & $0.66(0.34,1.31)$ \\
\hline & Parent/Partner/Husband & $21(29.6)$ & $172(25.7)$ & 1 & 1 \\
\hline & Yes & $47(66.2)$ & $436(65.1)$ & $1.05(0.57,1.59)$ & $1.20(0.65,2.23)$ \\
\hline & No & $24(33.8)$ & $234(34.9)$ & 1 & 1 \\
\hline \multirow{4}{*}{$\begin{array}{l}\text { Type of contraceptive you } \\
\text { know } \\
\text { Using any method to avoid } \\
\text { pregnancy currently }\end{array}$} & Short term & $18(26.1)$ & $113(17.9)$ & $1.62(0.91,2.88)$ & $1.95(1.04,3.66)^{*}$ \\
\hline & Long term & $51(73.9)$ & $520(82.1)$ & 1 & 1 \\
\hline & Yes & $38(53.5)$ & $138(20.6)$ & $4.44(2.69,7.34)$ & $5.41(2.73,10.72)^{*}$ \\
\hline & No & $33(46.5)$ & $532(79.4)$ & 1 & 1 \\
\hline
\end{tabular}

\subsection{Discussion}

This study revealed very worrisome figures of unsafe abortion and unsafe sexual practices among female Hawassa
University students; magnitudes of induced abortion all respondents were $9.6 \%$ and among those respondents who experience intercourse were $28.5 \%$. Which is three fold higher than national report of abortion in Ethiopia (2.3\%); but it is almost similar with a stud conducted in Wolayita 
Sodo University [39]. Similarly induced abortion among students of Kaduna State University, Northwestern Nigeria was $8.38 \%$ [40]. The possible reasons for a significant numbers of adolescent experienced induced abortions might be their developmental changes, being young people, living in higher institutions without direct parental supervision, freedom for initiating sexual activity, and lack of awareness about safer sex. This idea were supported by a study on Rift valley University students which states that institutions are getting sexually active and often take advantage of freedom from direct parental supervision and guidance to express their freedom by initiating sexual activity without adequate protection [41].

Other studies shows magnitude of induced abortion among Public Hospitals in Ethiopia was greater than the result of this study; 60.8\% in Eastern Tigray [42], 20.3\% in Debre Berhan town [1] and 33.6\% in Addis Ababa [29]. And countries other than Ethiopia Magnitude of abortion were also higher than the finding in this study; like $79.3 \%$ in Angola [26], 39\% incidence of induced abortion in Uganda [24], 64.1\% in Ghana [43], 12.2\% in Democratic Republic of Congo [18], 48\% in Zimbabwe [22], 53\% of pregnancies in Malawi are unintended, and that $30 \%$ of unintended pregnancies end in abortion [27] and 13.4\% in Mexico [23]. The discrepancy might be due to most studies listed here were conducted on antenatal care clinic by which almost all of the participants were married which exposes to unintended pregnancy and induced abortion as well. This justifications were supported by different studies which states that once females are on open access to legal intercourse the chance to have unintended pregnancy, consequently abortion is inevitable [42-44].

The findings of this study strongly imply that despite abortion is relatively liberalized; an effort to reduce unsafe abortion and subsequent maternal mortality, unsafe abortion remains to be a major problem affecting significant number of females. In this study pertinent predictors of induced abortion were found to be age, marital status, type of contraceptive they heard and using any method to avoid pregnancy. Several issues were mentioned by the respondents as most important reasons for resorting to abortion; reasons appear to underscore their understanding of the responsibilities of parenthood and family life. In addition to this significant numbers of students are engaged in unprotected sex and hence they are exposed to unintended pregnancy, abortion, sexual transmitted infections (STIs) and HIV/AIDS.

Respondents whose age less or equal to 19 were more likely to have induced abortion compared to those respondents with age greater than or equal to 20. Similarly a study in Northern Ethiopia among total community shows age less than 18 years were the risk factor of induced abortion [1]. In addition a study in Nigeria states that, $15-20$ years is the usual age group at which majority of women are first exposed to sexual intercourse and are therefore at a greater risk of exposure to complications of abortions, and other reproductive health problems [40]. This might be due to younger women are more liable to sexual coercion and rape that can lead to induced abortion and lack of access to contraceptives to prevent abortion.

Married respondents were more likely to have induced abortion compared to not marred respondents. Consistently a study in Addis Ababa also shows respondents who have stay more than one to two years were more likely to have induced abortion compared those not married respondents [29]. Similarly another study in Nigeria states that there is higher probability of demand for abortion by married couple who believe that they have had enough children [40]. This can be explained as increased unmet demand for contraceptive use in Ethiopia, more women have unplanned pregnancies, the demand for induced abortion increases. Contrary to this a study in Ghana states that married women were less likely to have an unsafe induced abortion [43]. Similarly a study in Democratic Republic of Congo shows single or separated or divorced women or widows had higher risk than married women [18].

Respondents who have heard only about short term contraceptive were more likely to have induced abortion compared to those who have heard only about long term contraceptives. Similarly a study in Addis Ababa University supports this idea and states that students who have better knowledge about long term contraceptive were less likely to have induced abortion [45]. This might be due to the fact that if they know long term contraceptive they may use long term contraceptives than short term contraceptives; because short term contraceptives have some disadvantages like need to be remembered every day and compliance cases may also be listed, this idea were supported by a study in Rift Valley University [41].

Respondents who have used methods to avoid pregnancy currently were more likely to have induced abortions compared to who haven't used any method. Similarly, female preparatory school students in Dabat District, Ethiopia using contraceptive currently were more likely to have induced abortion [32]. In addition a study in Ghana states is worth noting that $18.7 \%$ of women in the study who have induced abortion were on contraceptives [43]. This might be due those who were using contraceptive was practicing intercourse unlike who were not using contraceptive.

\section{Conclusion}

Induced abortion among Hawassa university female student was high. This study showed the independent predictors of abortion among Hawassa University students were age, marital status, type of contraceptive they know and using any method to avoid pregnancy currently.

This study had some limitations: Due to the fact that this study deals with very personal and sensitive issues such as sexual practice and induced abortion, obtaining an honest response among adolescent students was difficult. There may be social desirability bias so they may hide the real information. To the extent that in university adolescents differ from out of university adolescents, these findings may 
not be applicable to out of university adolescents. Since this study was targeted only on regular undergraduate students, who are not representative of all university students.

It is imperative that improved sexual health education is rendered and wider availability of Youth Friendly family planning services are realized in Universities and other places where young men and women live together. Institutions providing safe abortion services, should devise strategies to reach out for youth who are in need of their services and prevent youth from unsafe abortion and hence they prevented from unsafe abortion. Hawassa University student clinic should devise a way to make contraceptives, especially emergency contraceptives available for those in need, overcoming privacy barriers. Information, Education and Communications (IEC) programs on youth reproductive health should be properly implemented to address topics on unwanted pregnancy and safe abortion. Finally, alongside other efforts, lobbying for further liberalization of abortion services may serve to overcome perceived unnecessary barriers to access to safe abortion services by youth students and may solve blurry among care providers.

\section{Competing of Interest}

There is no competing of interest among the authors.

\section{Financial Support}

Nil.

\section{Abbreviations and Acronym}
AIDS: Acquired Immune Deficiency Syndrome
AOR: Adjusted Odds Ratio
CI: Confidence Interval
COR: Crude Odds Ratio
HIV: Human Immunodeficiency Viruses
HU: Hawassa University
IEC: Information, Education and Communications
IRB: Institutional Review Board
PPS: Probability Proportional to Size
SNNPR: Southern Nations Nationality Peoples Region
SRH: Sexual and Reproductive Health
SRS: Simple Random Sampling
STI: Sexual Transmitted Infections
UN: United Nation
WHO: World Health Organization

\section{Acknowledgements}

I am carrying out this work because of God, who gives me a chance to live with his grace and stay strong with his blessings.

This work can't be good as it is now, friends your support and advice made this proposal viable, thank you for your time. My wife, you are kind, patient and closest friend ever; I see you can hear me even I am silent thank you my sweet and
I love you.

My subjects, under graduate Hawassa University female students who have been included in this study; this research can't be a plan if you are not here, many thanks dear students.

\section{References}

[1] Alemayehu B, Addissie A, Ayele W, Tiroro S, Woldeyohannes D. Magnitude and associated factors of repeat induced abortion among reproductive age group women who seeks abortion Care Services at Marie Stopes International Ethiopia Clinics in Addis Ababa, Ethiopia. 2019; 16 (1): 76.

[2] Sarac M, Koc I. Increasing misreporting levels of induced abortion in Turkey: is this due to social desirability bias? Journal of biosocial science. 2019: 1-17.

[3] Worku A, Asfaw A, Gebremariam T, Tesfaye A, Wang X. Changes in the Prevalence of Induced Abortion in the Floating Population in Major Cities of China 2007-2014. BMC women's health. 2019; 16 (18).

[4] Ulbricht S, Beyer A, John U. Association between the use of free-of-charge intrauterine devices and a history of induced abortion: a retrospective study. BMC women's health. 2019; 19 (1): 120.

[5] Tong Q, Luo M, Xia WT, Zhou H, Wang Y, Hu HQ, et al. Motherwort injection in preventing post-abortion hemorrhage after induced abortion: A multi-center, prospective, randomized controlled trial. International journal of environmental research and public health. 2019.

[6] Geda YF. Determinants of teenage pregnancy in Ethiopia: A Case-control study, 2019. Current Medical Issues. 2019; 17 (4): 112 .

[7] Abraha D, Welu G. Knowledge of and Utilization of Emergency Contraceptive and Its Associated Factors among Women Seeking Induced Abortion in Public Hospitals, Eastern Tigray, Ethiopia, 2017: A Cross-Sectional Study. 2019; 2019: 7209274.

[8] Fekadu Y. Knowledge Attitude and Utilization of Emergency Contraception among Health Science and Medical Students of Arba Minch University, 2015. J Women's Health Care. 2017; 6 (383): 2167-0420.1000383.

[9] Pilecco FB, Guillaume A, Ravalihasy A, Desgrees du Lou A. Induced Abortion and Migration to Metropolitan Paris by SubSaharan African Women: The Role of Intendedness of Pregnancy. Journal of immigrant and minority health. 2019.

[10] Pena RN, Fernandez C, Blasco-Felip M, Fraile LJ, Estany J. Genetic Markers Associated with Field PRRSV-Induced Abortion Rates. Viruses. 2019; 11 (8).

[11] Niinimaki M, Jalanko E, Leppalahti S, Heikinheimo $O$, Gissler M. The Risk of Psychiatric Morbidity Following Teenage Induced Abortion and Childbirth-A Longitudinal Study From Finland. PloS one. 2019.

[12] Cheng HC, Black K. Views and practices of induced abortion among Australian Fellows and trainees of The Royal Australian and New Zealand College of Obstetricians and Gynaecologists: A second study. 2019. 
[13] Coast E, Murray SF. "These things are dangerous": Understanding induced abortion trajectories in urban Zambia. Social science \& medicine (1982). 2016; 153: 201-9.

[14] Lindgren M, Faxelid E, Oguttu M, Klingberg-Allvin M, Ishoso DK. Analysis of induced abortion-related complications in women admitted to referral health facilities in Kinshasa, Democratic Republic of the Congo. Reproductive health. 2018; 13 (8): e0203186.

[15] Birdsey G, Crankshaw TL, Mould S, Ramklass SS. Unmet counselling need amongst women accessing an induced abortion service in KwaZulu-Natal, South Africa. Contraception. 2016; 94 (5): 473-7.

[16] Gebremariam H, Mannisto J, Mentula M, Bloigu A, Gissler $\mathrm{M}$, Heikinheimo O. Induced abortion and future use of IVF treatment; A nationwide register study. BioMed research international. 2019; 14 (11): e0225162.

[17] Tshefu A. K, Coppieters Y, Scott R. H, Filippi V, Moore A. M, Acharya R, et al. Setting the research agenda for induced abortion in Africa and Asia. Reproductive health. 2018; 142 (2): 241-7.

[18] Martinez S, Morris C. N, Rafanoharana R. V, Wheeler E, Lentiro K, Gebru T. Risk factors of induced abortion among preparatory school student in Guraghe zone, Southern region, Ethiopia: a cross-sectional study. Sexual and reproductive health matters. 2019; 19 (1): 115.

[19] De AK, Kumar BS. Evaluation of isosorbide-5-mononitrate as a cervical ripening agent prior to induced abortion in contrast to misoprostol- a randomized controlled trial. 2019; 62 (5): 313-21.

[20] Brooks N, Bendavid E, Miller G. USA aid policy and induced abortion in sub-Saharan Africa: an analysis of the Mexico City Policy. The Australian \& New Zealand journal of obstetrics \& gynaecology. 2019; 7 (8): e1046-e53.

[21] Sully EA. Abortion in Zimbabwe: A national study of the incidence of induced abortion, unintended pregnancy and post-abortion care in 2016. Reproductive health matters. 2018; 13 (10): e0205239.

[22] Behulu G. K, Fenta E. A, Aynalem G. L. Repeat induced abortion and associated factors among reproductive age women who seek abortion services in Debre Berhan town health institutions, Central Ethiopia, 2019. BMJ sexual \& reproductive health. 2019; 12 (1): 499.

[23] Prada E, Atuyambe L. M, Blades NM, Bukenya J. N, Orach C. G, Bankole A. Incidence of Induced Abortion in Uganda, 2013: New Estimates Since 2003. PloS one. 2016; 11 (11): e0165812.

[24] Alexander L. T, Fuentes-Rivera E. Utilisation of secondtrimester spontaneous and induced abortion services in public hospitals in Mexico, 2007-2015. 2019.

[25] de Almeida N, Teixeira A, Capoco Sachiteque A, Molina JR, Dos Prazeres Tavares H, Ramalho C. Characterisation of induced abortion and consequences to women's health at Hospital Central do Huambo - Angola. Journal of obstetrics and gynaecology: the journal of the Institute of Obstetrics and Gynaecology. 2019: 1-6.

[26] Polis CB, Mhango C, Philbin J, Chimwaza W, Chipeta E, Msusa A. Incidence of induced abortion in Malawi, 2015. PloS one. 2017; 12 (4): e0173639.
[27] Kabiru C. W, Ushie BA, Mutua M. M, Izugbara C. O. Previous induced abortion among young women seeking abortion-related care in Kenya: a cross-sectional analysis. BMC pregnancy and childbirth. 2016; 16: 104.

[28] Moore A. M, Gebrehiwot Y, Fetters T, Wado Y. D, Bankole A, Singh S, et al. The Estimated Incidence of Induced Abortion in Ethiopia, 2014: Changes in the Provision of Services Since 2008. Reproductive health. 2016; 42 (3): 111-20.

[29] Biney A. A. E, Atiglo D. Y. Examining the association between motivations for induced abortion and method safety among women in Ghana. Women \& health. 2017; 57 (9): 1044-60.

[30] Rodriguez-Alvarez E, Borrell L. N, Gonzalez-Rabago Y, Martin U, Lanborena N. Induced abortion in a Southern European region: examining inequalities between native and immigrant women. International journal of public health. 2016; 61 (7): 829-36.

[31] Kebede M. M, Bazie B. B, Abate G. B, Zeleke A. A. Knowledge of Abortion Legislation Towards Induced Abortion Among Female Preparatory School Students in Dabat District, Ethiopia. African journal of reproductive health. 2016; 20 (4): 13-21.

[32] Riley T, Moore A. M, Crowell M, Nyandoro M. T, Madzima $\mathrm{B}$, Chipato $\mathrm{T}$, et al. Decision-making preceding induced abortion: a qualitative study of women's experiences in Kisumu, Kenya. Plo S one. 2018; 15 (1): 166.

[33] Gbagbo F. Y, Amo-Adjei J, Laar A. Decision-Making for Induced Abortion in the Accra Metropolis, Ghana. African journal of reproductive health. 2015; 19 (2): 34-42.

[34] Maina B. W, Mutua M. M, Sidze E. M. Factors associated with repeat induced abortion in Kenya. BMC public health. 2015; 15: 1048 .

[35] Directorate $\mathrm{Rb} \mathrm{PaI} \mathrm{T}$. A brief overview of Hawassa University: $\quad$ http://wwwhueduet/hu/indexphp/abouthu/overviewhtml 2018.

[36] Erena G, Kerbo A. A. Unwanted pregnancy and associated factors among female students of Madawalabu University Bale Zone, Oromia Region south east, Ethiopia. Science Journal of Public Health. 2015; 3 (1): 50-5.

[37] Gelaye A. A, Taye K. N, Mekonen T. Magnitude and risk factors of abortion among regular female students in Wolaita Sodo University, Ethiopia. BMC women's health. 2014; 14: 50 .

[38] Oyefabi A. O, Nmadu A. G, Yusuf M. S. Prevalence, perceptions, consequences, and determinants of induced abortion among students of the Kaduna State University, Northwestern Nigeria. Journal of Medicine in the Tropics. 2016; 18 (2): 86.

[39] Abera M, Ofori K. N, Opito R, Nanfuka M, Mugenyi L, Etukoit $\mathrm{MB}$, et al. Unprotected Sex and Associated Factors among Adolescent Students of Rift Valley University Jimma Campus, Jimma Town, South West Ethiopia: Institution Based Cross Sectional Study. International Journal of HIV/AIDS Prevention, Education and Behavioural Science. 2019; 5 (1): 1.

[40] Gebremariam H, Lentiro K, Gebru T. Risk factors of induced abortion among preparatory school student in Guraghe zone, Southern region, Ethiopia: a cross-sectional study. BioMed research international. 2019; 19 (1): 115. 
[41] Boah M, Bordotsiah S. Predictors of Unsafe Induced Abortion among Women in Ghana. 2019; 2019: 9253650.

[42] Kassa S, Molla A, Cherie N. Sexual Coercion and Determinant Factors among Female Students in Wollo University, Ethiopia. 2019.

[43] Kebede A, Molla B, Gerensea H. Assessment of risky sexual behavior and practice among Aksum University students, Shire Campus, Shire Town, Tigray, Ethiopia, 2017. BMC research notes. 2018; 11 (1): 88.
[44] Yared A, Sahile Z, Mekuria M. Sexual and reproductive health experience, knowledge and problems among university students in Ambo, central Ethiopia. Reproductive health. 2017; 14 (1): 41.

[45] Tamire W, Enqueselassie F. Knowledge, attitude, and practice on emergency contraceptives among female university students in Addis Ababa, Ethiopia. Ethiopian Journal of Health Development. 2007; 21 (2): 111-6. 